\title{
HACIENDAS FORALES Y REFORMAS BORBONICAS. NAVARRA, 1700-1808
}

MARIO GARCIA-ZUÑIGA

Universidad del Pais Vasco

\section{RESUMEN}

Durante los siglos XVI y xVII el sistema fiecal de la Monarquia hispana se habin aus tentado en los recureos que proporcionabe la corone de Castilla. En el xvil los Borbones emprendieron una serie de reformas para integrar en eate sistema a aquellos territorios que no contribuian. La mayor parte de los estudios se han centrado en los nuevos regimenes fiscales que ee cublecen en la corona de Aragón. Mucho menos conocido es su impacto en Vaccongadas y Navarra, cuyas haciendas forales tumbién se vieron modificadas, aunque siguieran disfrutando de una amplia exoneración tributaria. El objetivo de este artículo es analizar cómo se materializaron estos cambios en el reino de Navarra.

\section{ABSTRACT}

In the 16th and 17th centuries the fiscal oyotem of the Spanish monarchy had been sustained by the resources provided by Castile. In the 18th century the Bourbons undertook a series of reforms to integrate those territories which did not contribute. So far much research has been done on the new fiscal systems eatrablished in the realms of the crown of Aragon, but the impact on the Basque Country and Navarre is leas known. The statutory finances of these territories were modified, although they continued to enjoy tax exemption. This paper aims at analysing how such changes materialized in the Kingdom of Navarre.

De todo el feudalismo desarrollado ${ }^{\prime}$ el xvin es, sin duda, el siglo que más interés ha despertado entre los historiadores de la hacienda española. En.

1 El concepto de feudalismo desarrollado -el Spätfeudalismus alemán, el féadalisme centralisé 
tre otras mültiples razones, posiblemente ello se deba a las mayores oportunidades, que no facilidades, que encuentran los investigadores para elaborar series con las cuales trazar la evolución de ingresos y gastos de las diversas haciendas hispanas. De esta forma, y gracias a los trabajos ya antiguos de Canga Argüelles y de Lopez Juana Pinilla y a otros más recientes ${ }^{2}$, nuestra imagen sobre la fiscalidad del setecientos es bastante sólida.

Al igual que sucediera en el Xvi o en el Xvil, el principal problema al que tuvo que hacer frente el real erario durante esta centuria fue cómo adecuar sus recursos a unas necesidades financieras crecientes, básicamente originadas por los gastos militares '; fuera del monopolio de la coerción, la monarquia hispana, al igual que los demás estados «modernos», habia asumido muy pocas cargas. El régimen de encabezamientos o el arriendo como prácticas mayoritarias para recaudar los impuestos había reducido al mínimo la burocracia 4; la justicia, cuando no se habia enajenado, se autofinanciaba merced a las tasas y multas impuestas por los tribunales; enseñanza y sanidad corrian por cuenta de las instituciones eclesiásticas; la infraestructura viaria la costeaban los propios pueblos... Así pues, el principal desembolso de la fiscalidad de estado lo constituían las partidas destinadas a ejército y marina's. Durante los conflictos, las cargas se elevaban por razones obvias; en tiempos de paz no disminuian demasiado: había que abonar las soldadas, prepararse para conflictos futuros y hacer frente a las deudas contraídas durante los anteriores.

Expandir los recursos con cambios radicales en el sistema impositivo era algo totalmente ilusorio; no en vano desde los tiempos medievales el desarrollo del fisco regio se había llevado a cabo sin interferir en la percepción del

o al ffodalité tandive francesas - define con mayor precisión que los de edad moderna o Antiguo Régimen la realidad económica, social y politica de los siglos xv-xvII. Subyacente en todos sus trabajos, el modelo económico fue explicitado en nuestro pais por Fernandez de Pinedo (1979, pp. 76-81; 1980, pp. 11-16). Cf. Kriedte (1982, pp. 9-28) y, aunque limitándose a la propiedad feudal de la tierre, Soboul (1985).

2 La lista seria demasiado larga Por su amplitud cronolögica debemos mencionar, además del de Artola (1982), los de Fernández Albadalejo (1977), Merino (1987) y Pieper (1988).

3 Para la estructura del gasto, véanse Ozanam (1978, pp. 57.59), Fernández de Pinedo (1980, pp. 85.87; 1991, pp. 94-96), Merino (1981, p. 156; 1987, pp. 103-171), Barbier y Klein (1985, pp. 480-483), Pieper (1988, pp. 148-149). Cf. para Francia, Morineau (1980, pp. 301 y ss.) y, para Inglaterra, Brewer (1988, pp. 29-42). Ello no excluye la existencia de una desorganización recaudatoria, aspecto sobre el que últimamente viene insistiendo Fontana $(1989,1990)$.

4 Aunque centrado en el XVI, véase Fortea (1990, pp. 461 y s5.). Esta debilidad de la burocracia no es un rasgo exclusivo de la corona de Castilla, ya que incluso en una monarquía tan *centralizada como la francesa aquélla era también poco numerosa, como para el siglo xvi han puesto de relieve Dessert (1984, cap. 3) y Bayard (1988, pp. 52-59, 266).

5 Braudel (1976, cap. 2, pp. 251-254), Fernández de Pinedo (1980, pp. 85-86), Hocquet (1987, p. 34). Conviene, sin embargo, matizar la idea de que todo el dispendio bélico fuera improductivo. Véase Fernández de Pinedo (1991, pp. 95-96). 
principal ingreso con que contaban los señores: la renta de la tierra ${ }^{6}$. De ahí que las reformas se vieran siempre limitadas en este sentido. $Y$ no quiere ello decir que los Borbones no tratasen de modificar el régimen fiscal vigente, pero su resultado fue un rotundo fracaso. El paradigma es el fallido intento de Ensenada para sustituir el abigarrado conjunto de las rentas provinciales por una Unica Contribución que gravase la renta patrimonial y personal '; no mucha mejor suerte correría tiempo después la de efrutos civilesw, aunque su alcance fuera más limitado 8 .

A fin de incrementar su capacidad recaudatoria, la nueva dinastia adoptó ya durante la guerra de Sucesión una serie de disposiciones tendentes a reorganizar la hacienda castellana 9. Estas proseguirian durante el resto de la centuria ${ }^{10}$, aunque sin alterar uno de los rasgos definitorios de la fiscalidad, su carácter indirecto. Pero la racionalización del sistema tributario no podía circunscribirse únicamente a la corona de Castilla, sino que pasaba por implicar en las cargas generales de la monarquia a aquellos territorios que hasta entonces o no contribuian o pagaban muy poco. En este sentido, el establecimiento de nuevos regimenes fiscales en los reinos de la corona de Aragón es, sin duda, la reforma más espectacular, no sólo del reinado de Felipe $V$, sino de todo el setecientos, y, lógicamente, la que más páginas ha inspirado ". Al quedar al margen de los decretos de Nueva Planta, Vascongadas y Navarra seguirian gozando de una amplia exoneración tributaria. Sin embargo, y aunque subsistan los rasgos diferenciadores, durante el XVIII sus privilegiadas haciendas forales también iban a verse modificadas, al tener que coadyuvar en mayor grado del que lo venían haciendo al gasto de la monarquía. En gran medida, los cambios que tienen lugar en esta centuria en la fiscalidad vasca ${ }^{12}$ y

- Fernández de Pinedo (1980, p. 12).

7 Matilla Tascón (1947), Fontana (1973, pp. 25-27), Otazu (1978). El proyecto, que ya en 1703 habia intentado Orry (Kamen, 1974, pp. 252-253), acabara por convertirse en uno de los mitos de los hacendistas españoles del primer tercio del XIX. Véase Fontana (1972).

- Establecida en 1785 y modificada en 1794, seria finalmente denogada en 1817. Anes (1974, pp. 26-30).

- Kamen (1974, pp. 238 y ss.).

10 Véanse Fontana (1973, pp. 18-43), Barbier (1977), Fernández de Pinedo (1980, pp. 74-85), Artola (1982, pp. 249-267); para las rentas generales, Garcia-Cuenca Ariati (1983, pp. 238 y ss.).

"I Reformas que no se limitaron tan sólo a exigir cantidades presuntamente equivalentes de las rentas provinciales castellanas. Ademis del estudio de Kamen (1974, pp. 337-390), limitado cronológicamente al periodo de la guerra, véanse, para el caso catalán, Mercader i Riba (1961), Nadal Farreras (1971) y Fernández de Pinedo (1985); para Valencia, Romeu Llorach (1981) y, aunque referido sólo a la ciudad, Correa Ballester (1986). Menos afortunados han sido Aragón y Baleares; sobre el primero, Forcadell (1985, pp. 232-238) y Peiró (1988).

12 Una visión general de les haciendas vascas durante el xvm en Bilbao (1984, 1991, pp. 55 . 58). Para el caso guipuzcoano es imprescindible la consulta de Mugartegui (1990). 
navarra son la culminación de los que se habían ido articulando durante el XVII y preludio de lo que sucederá en el XIX ${ }^{13}$.

\section{LAS TRANSFORMACIONES DE LA FISCALIDAD NAVARRA EN EL SETECIENTOS}

Heredados de la baja Edad Media, los principales ingresos con que habia contado la monarquía en el reino de Navarra durante el mil quinientos y el mil seiscientos eran las escasas sumas procedentes del ejercicio de la justicia y del aprovechamiento económico de un realengo cada vez más mermado y las más cuantiosas que cada año obtenía de la renta de tablas y, con una menor regularidad, de los donativos - voluntarios sólo de nombre- que las cortes habian de conceder cada vez que la corona decidia reunirlas. El surgimiento a mediados del xvi de una fiscalidad distinta y paralela a la del monarca hará que desde entonces coexistan una hacienda real y una foral -conocida con el nombre de Vínculo-, esta última de caracteres mucho más modernos al apoyarse básicamente en dacios sobre el consumo y la circulación: estancos del tabaco y chocolate y gravámenes sobre las exportaciones de lana.

La política hacendística llevada a cabo por los Borbones en la Navarra del xvin se plasmó, más que en el establecimiento de nuevos tributos, en cambios en su gestión, tratando asi de optimizar unos recursos ya existentes. Por un lado, Felipe $\mathrm{V}$ y sus sucesores trataron de racionalizar las rentas ordinarias, fuesen o no de titularidad real; por otro, presionarán sobre los Tres Estados no sólo para obtener donativos más sustanciosos, sino también para poder disponer libremente del monto de los mismos. No obstante, las modificaciones que experimentaron éstos no fueron responsabilidad única de la nueva dinastía, habiéndose iniciado ya en los tiempos de Carlos II ${ }^{14}$. Forzados los cambios por un aumento del gasto defensivo, desde 1684 y junto al tradicional servicio de cuarteles y alcabalas 15 comenzó a otorgarse para

13 Fernández de Pinedo (1987).

14 En el marco de lo que Artola (1982, pp. 216-221) ha llamado la reforma de Oropesa-Los Vélez. Cf. Garzón Pareja (1980, pp. 274-292).

15 Hesta los cambios introducidos en las cortes de 1684-1685 el donativo se componia de un determinado número de cuarteles y de cuatro tandas de alcabala. Los primeros eran un viejo impuesto directo medieval que ya desde fines del siglo xrv se encontraba encabezado. A mediados del xvi su monto quedó petrificado en la suma de 6.700 rs. plata (1 real plata ( 36 mrs.) -64 mrs. vn.). De esta forma, y seguin las necesidades financieras del monarca, los Tres Estados concedian un mayor o menor número de cuarteles; en torno a los 39-40 a fines del quinientos. Por lo que respecta a la alcabala, ésta nunca se convertirí en Navarra en un dacio permanente, conservando siempre su carácter de medio de pago del servicio, y, a diferencia de la castellana, su tipo 
aquel fin una creciente cantidad de dinero, a recaudar mediante repartos foguerales ${ }^{16}$.

Nuevas transformaciones se producen en las cortes de Pamplona de 171617, al concederse como parte del donativo de las mismas los derechos que produjera el pago por los naturales de aranceles en la importación ${ }^{17}$, del que por ley se encontraban eximidos. Ello ponia fin de facto a los privilegios que gozaban los navarros para introducir cualquier mercancía sin ningún tipo de trabas. El recurso a los gravámenes arancelarios permitia beneficiarse del aumento del consumo, y por ende del tráfico mercantil, que se produce en la coyuntura alcista del setecientos sin que los contribuyentes tuvieran desde el punto de vista psicológico una excesiva sensación de carga, pero también elevar los caudales ofertados sin incrementar los cuarteles, es decir, no interfiriendo en la renta de la tierra.

Desde las cortes de $1724-26$ se concretara de antemano el monto del otorgamiento, que además se haría efectivo, parcial o totalmente, en el momento de publicarse la ley. Con anterioridad, tanto para conocer la cuantia global del servicio como para cobrarla, el monarca habia de esperar a que éste se hubiera recaudado en los plazos que la ley estipulaba, si bien el reino podía decidir adelantarlo, en todo o en parte, ya por las necesidades del momento o porque no se habían cumplido aquéllos. Para aprontar el donativo la hacienda foral recurrirá bien a sus propios fondos, bien al empréstito. Esto último, aunque incrementaba la cantidad a repartir con sumas adicionales para el abono de los réditos hasta amortizar la deuda, permitía distribuir las cargas en un periodo de tiempo más dilatado y, por lo tanto, no elevaba repentinamente la presión fiscal. Las reformas prosiguen en la siguiente convocatoria a cortes. Hasta entonces, y con alguna que otra salvedad, los servicios ofertados habían de invertirse integramente en el reino; a partir de las de 1744 una parte cada vez mayor de los mismos saldrá fuera de Navarra, con destino a la Tesorería General de Madrid o, lo más frecuente, a las tesorerías regionales del ejército. Los cambios culminarán en las cortes de Pamplona de 1765-66, cuando, bajo presiones

impositivo no se elevara del 5 por 100. Igualmente encabezada, en este caso cuando menos desde las últimas décadas del xv, en los años cuarenta de la siguiente centuria se fosiliza en la suma de 39.860 rs. plata, a recaudar, al menos teóricamente, en cuatro tandas o pagos trimestrales. Para éstas y otras precisiones, véase Garcia-Zúñiga (1990, pp. 199-201).

16 Consistentes en distribuir aquélla entre el número de vecinos. De esta forma se acentuaba la desigualdad fiscal existente: aparentemente equitativo, el impuesto de capitación grava de forma igual a vecinos con muy diferentes niveles de riqueza.

17 Novissima Recopilacion... (NR), 1.2.63. 
de la corona, el donativo se reduce a una cantidad fija, integra y efectiva ${ }^{18}$. Mientras antes lo que el rey recibía era el producto de los cuarteles y alcabalas más una suma variable de dinero que el reino le otorgaba, ahora los Estados van a establecer medios para que la hacienda foral recobre la cuantia aprontada. Su reembolso se va a hacer por tres vias: cuarteles y alcabalas - que técnicamente han perdido su carácter originario de tributo, convirtiéndose en un procedimiento de cobro-, repartimientos foguerales y gravámenes arancelarios concedidos por la corona, ya que las cortes, al no tener potestad tributaria, no pueden imponerlos por sí solas.

\section{CUADRO 1}

Comparación entre la propuesta inicial del donativo y la definitiva (000 rs. plata)

\begin{tabular}{|c|c|c|c|c|c|c|}
\hline \multirow{3}{*}{ DONATIVOS } & \multicolumn{2}{|c|}{$\begin{array}{l}\text { PROPUESTA } \\
\text { INICIAL }\end{array}$} & \multicolumn{2}{|c|}{$\begin{array}{l}\text { CONCESION } \\
\text { DEFINITIVA }\end{array}$} & \multirow{3}{*}{$3 / 1 \%$} & \multirow{3}{*}{$4 / 2 \%$} \\
\hline & Suma total & En efectivo & Suma total & En efectivo & & \\
\hline & 1 & 2 & 3 & 4 & & \\
\hline $1743-44 \ldots \ldots$. & 1.600 & 800 & 1.600 & 1.200 & & 150 \\
\hline $1757 \ldots \ldots \ldots$ & 1.200 & 400 & 1.200 & 480 & & 120 \\
\hline $1765-66 \ldots \ldots$ & 1.440 & 480 & 1.440 & 1.440 & & 300 \\
\hline $1780-81 \ldots \ldots$ & 2.080 & 2.080 & 2.400 & 2.400 & 115 & \\
\hline $1794-97 \ldots \ldots$ & 1.440 & 1.440 & 2.000 & 1.600 & 139 & \\
\hline
\end{tabular}

FuENTE: Cuadernos de las leyes... (CC), leyes del servicio correspondientes.

Las modificaciones que se producen en la estructura del servicio desde 1684 hasta 1765 refuerzan no sölo la imagen de que éste nunca fue evoluntariow en su concesión, por más que las instituciones navarras se esfuercen en mantener, cuando menos nominalmente, este atributo, sino que también habia dejado de ser agracioso», entendiendo por ello, tal y como aquéllas lo hacian, la libertad de servir con una mayor o menor ayuda monetaria. Salvo en el otorgamiento de 1709, en el que no aceptó las condiciones pero sí el importe, el rey siempre había admitido lo que el reino le ofrecía. Sin embargo, desde la convocatoria de 1744 la corona nunca aprobará la propuesta inicial, bien por-

18 Véase el informe de Isidoro Gil de Jaz de 19 de marzo de 1764 al marqués de Esquilache. AGS, SSH, leg. 506. 
que deseara un aumento del efectivo, bien porque el monto final le pareciese escaso. Esta resistencia forzará a los Estados a excitarse en su «amor y celon, replicando dos y tres veces hasta obtener, obviamente tras un incremento de la cuantía a aprontar o de la definitiva, la aprobación regia.

\section{CUADRO 2}

Estructura del donativa, 1700-1806 (medias decenales en rs. plata)

\begin{tabular}{|c|c|c|c|c|c|}
\hline & $\begin{array}{l}\text { Cuarteles y } \\
\text { alcabalas }\end{array}$ & $\begin{array}{l}\text { Repartos } \\
\text { foguerales }\end{array}$ & $\begin{array}{l}\text { Graudmenes } \\
\text { arancelarios }\end{array}$ & $\begin{array}{c}\text { Del estanco } \\
\text { del } \\
\text { cbocolate }\end{array}$ & Total \\
\hline $1700-09$ & 64.927 & 98.190 & 3.399 & & 166.516 \\
\hline $1710-19 \ldots \ldots \ldots \ldots \ldots \ldots$ & 137.554 & 28.776 & 9.653 & & 175.983 \\
\hline $1720-29 \ldots \ldots \ldots \ldots \ldots \ldots$ & 87.003 & 33.822 & 13.480 & & 134.305 \\
\hline $1730.39 \ldots \ldots \ldots \ldots \ldots$ & 0 & 0 & 16.850 & & 16.850 \\
\hline $1740-49 \ldots \ldots \ldots \ldots \ldots \ldots$ & 55.931 & 42.250 & 26.102 & & 124.283 \\
\hline $1750-59 \ldots \ldots \ldots \ldots \ldots \ldots$ & 29.689 & 17.185 & 37.105 & & 83.979 \\
\hline $1760-69 \ldots \ldots \ldots \ldots \ldots \ldots$ & 91.827 & 35.474 & 52.367 & & 179.668 \\
\hline $1770-79 \ldots \ldots \ldots \ldots \ldots$ & 62.138 & 18.290 & 15.670 & & 96.098 \\
\hline $1780-89 \ldots \ldots \ldots \ldots \ldots \ldots$ & 139.911 & 58.426 & 66.774 & 12.800 & 277.811 \\
\hline $1790-99$................. & 106.353 & 50.406 & 22.283 & 4.800 & 183.842 \\
\hline $1800.06 \ldots \ldots \ldots \ldots \ldots \ldots$ & 190.623 & 103.104 & & & 342.297 * \\
\hline
\end{tabular}

FUENTE: Garcia-Zúniga (1991: I, 241-42).

* Agregados los 340.000 rs. aprontados por la hacienda foral -127.500 en 1801 y 212.500 en 1805 - por cuenta del servicio que se habia de hacer. Archivo General de Navarra (AGN), Cuarteles y alcabalas, leg. 8, c. 51; Cuentas del Vinculo, libro 5.

Aislando el siglo xvm, las transformaciones del donativo en esta centuria no parecen económicamente importantes: a principios del XIX apenas se han duplicado los niveles de 1700-09 y, debido a la cada vez menor frecuencia con que el rey reunia las cortes, existian numerosos años en los que aquél no se recaudaba. Sin embargo, si las analizamos en la larga duración, se observa cómo entre 1670 y visperas de la guerra contra el francés las sumas se han cuadruplicado ${ }^{19}$. Pero, además, las reformas no se limitaron a elevar el

19 Remontóndose asi la caída iniciada en 1640 y que toca fondo en los años setenta. GarciaZúñiga (1991, cap. I, pp. 232-233 y 243-244). 
monto de los servicios, sino que también afectaron a su inversión, reduciéndose drásticamente la parte que, en forma de mercedes y acostamientos, iba a parar antes a la nobleza ${ }^{20}$. En consecuencia, tanto por la vía del ingreso como por la del gasto, los navarros se vieron obligados a contribuir a las cargas generales de la monarquia de una forma creciente conforme avanzaba la centuria.

\section{GRAFICO 1}

Ingresos y gastos del estanco del tabaco, 1700-1799

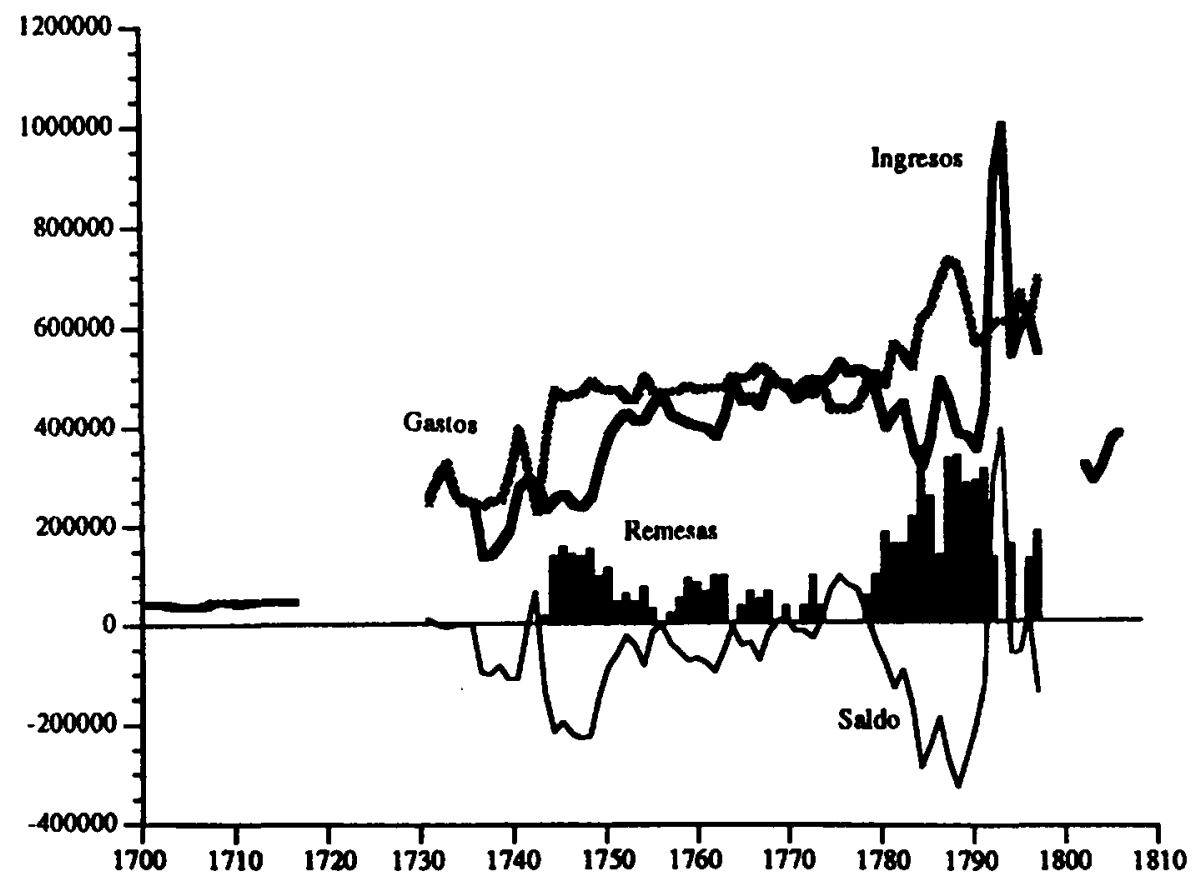

FUENTE: Garcia-Züñiga (1991: II, 158-61).

Los principales cambios en la gestión de las rentas afectaron al estanco del tabaco y a las aduanas y el argumento esgrimido fue el eterno problema del contrabando. Este se habia agravado en la segunda mitad del xvir, tras conce-

20 Mientras en los siglos XVI y XVI absorbian la mitad del dispendio, en 1780 representaban únicamente un 6 por 100. Sobre los cambios en la estructura del gasto, Garcia-Zúñiga (1993). 
derse a la hacienda foral en 1642 el monopolio del tabaco. El menor precio de este último en Navarra propició su tráfico ilegal hacia Castilla, añadiéndose al resto de las mercancias que traspasaban fácil y clandestinamente las fronteras entre ambos reinos. Intentando acabar con los fraudes, en 1716 y por real cédula de 17 de septiembre la corona comunicaba a las cortes reunidas en Pamplona que habia decidido hacerse cargo del estanco, la principal renta que nutria las arcas del Vínculo ${ }^{21}$. Tras un tenso debate se acabó cediendo su administración a ala persona que vuestra Magestad determinare por tiempo de ocho años repartidos en dos cuatrienios». El rey se comprometía a mantener los precios vigentes y el arriendo quedaba fijado en la suma de 46.500 rs. plata -la misma en que lo había rematado el último arrendador y que permanecerá inalterada durante toda la centuria - a pagar por tercios, uno de ellos anticipado ${ }^{22}$. Desde entonces, y pese a las cláusulas de salvaguarda, el tabaco puede considerarse de hecho como un tributo más de la real hacienda, llegando a convertirse mediado el siglo en su principal fuente de ingresos en Navarra.

La primera resolución que adoptó la monarquía fue el incremento de las patrullas de vigilancia, cuya labor se veía reforzada, además, con la ayuda que les prestaban efectivos militares. Esta medida tuvo unos resultados cuantitativos evidentes: entre 1716 y 1731 -carecemos de datos para los años intermedios- las entradas se quintuplican. Aunque las proporciones de este alza deben matizarse, ya que para el primer periodo tan sólo disponemos del precio de los arriendos y éstos nos ocultan los valores reales, cualquiera que fuese su magnitud es innegable que se produjo un espectacular crecimiento, el cual dificilmente podría explicarse por el simple aumento del número de consumidores.

El éxito, sin embargo, fue sólo parcial, ya que la corona no pudo acabar con los fraudes. En 1736, tras dos años de descenso de los rendimientos, la real hacienda atribuia su elevado número a «la suavidad y blandura con que [...] eran castigados por las leyes de este dicho nuestro reyno, de modo que, en vez de dexarlos escarmentados, tenian en ellas una tacita licencia de delinquir en el mencionado delitow. Por ello, y mientras no se reuniera de nuevo a los Tres Estados para que legislasen al respecto, se elevan las penas para contrabandistas y cómplices ${ }^{23}$. Aunque la Diputación reclamó contrafuero porque se habia actuado al margen de las cortes, quebrantándose además lo estipulado en el contrato de arrendamiento, aquéllas serán «legalizadas» en la convocatoria de

21 AGN, Vínculo, leg. 3, c. 57.

22 NR, 1.2.79, AGN, Vinculo, $\operatorname{leg} 3$, c. 68.

23 AGN, Vinculo, leg 4, c. 46. 
1743-44 24. Pese a ello, el declive recaudatorio continuó. Y como el aumento de los empleados en el resguardo del tabaco había disparado el dispendio -sus salarios absorbían entre el 60 y 70 por ciento de la data-, el producto de la renta, que anteriormente apenas había bastado para hacer frente a los desembolsos, fue entonces insuficiente: entre 1737 y 1741 se produjo un fuerte déficit que hubo de cubrirse inyectando dinero desde Castilla. Por esta causa, y considerando además la corona que no había logrado su propósito de poner fin al tráfico ilícito, en 1742 se restituia a la hacienda foral el control de la renta ${ }^{25}$. Bien poco duraría su gestión. Los ingresos apenas crecen un 5 por ciento y, si se obtuvieron beneficios, fue debido sobre todo a un recorte de los gastos, y más en concreto, de las partidas destinadas al resguardo; en consecuencia, el contrabando volvió a aumentar ${ }^{26}$.

\section{CUADRO 3}

Distribución de los gastos del estanco del tabaco (rs. plata)

\begin{tabular}{|c|c|c|c|c|}
\hline & 1750 & $\%$ & 1767 & \% \\
\hline Salarios administración .... & 81.456 & 17,05 & 128.171 & 25,50 \\
\hline Salarios resguardo $\ldots \ldots \ldots \ldots \ldots \ldots \ldots \ldots \ldots \ldots$ & 323.105 & 67,61 & 307.692 & 61,21 \\
\hline Gastos administración $\ldots . \ldots \ldots \ldots \ldots \ldots \ldots$ & 8.580 & 1,80 & 10.874 & 2,16 \\
\hline Arrendamiento $\ldots \ldots \ldots \ldots \ldots \ldots \ldots \ldots \ldots \ldots$ & 46.500 & 9,73 & 46.500 & 9,25 \\
\hline \multirow[t]{2}{*}{ 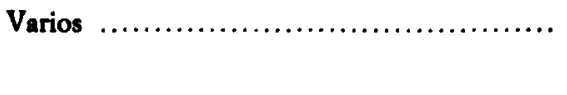 } & 18.224 & 3,81 & 9.454 & 1,88 \\
\hline & 477.865 & 100,00 & 502.691 & 100,00 \\
\hline
\end{tabular}

FUENTE: AGS, DGR, 1.' remesa, legs. 2452.53.

Entretanto, bien pudo considerar la monarquia que, a pesar de todo, no habia hecho tan mal negocio. El control del estanco le habia permitido trasladar al interior de Navarra parte de la vigilancia que hasta entonces se realizaba

24 La única modificación que se produce es una rebaja de las penas impuestas a los naturales. En el arrendamiento de 1765 se igualarín las sanciones. CC, 1743.1744, ley 76; 1765.1766, ley 64.

${ }^{25}$ La real cédula de 8 de mayo disponia que los guardas de Castilla y Aragón pudieran entrar en Navarra en persecución de los contrabandistas. Ante las protestas de la Diputación, en octubre se anulaba esta medida. AGN, Vinculo, leg. 4, c. 69.

${ }^{26}$ Buena prueba de ello es el hecho de que las instituciones del reino se vieran obligadas a duplicar el número de guardas, que pasaron de 41 en 1742 \& 86 en 1743. AGN, Vinculo, leg. 4, c. 90, y leg. 5 , c. 5 . 
al otro lado de sus fronteras y cuyo coste gravitaba única y exclusivamente sobre el erario real. El enorme incremento de rondas y patrullas que tuvo lugar en el reino pirenaico permitió reducirlas en las zonas limítrofes castellanoaragonesas y, al estar aquéllas financiadas, cuando menos en parte, con los impuestos que pagaban los propios navarros, la real hacienda ahorraba costes. Por RO. de 26 de marzo de 1744 la corona volvia a hacerse cargo del estanco, esta vez de una forma definitiva ${ }^{27}$. Y de nuevo, la primera medida adoptada fue el aumento de los guardas. A partir de entonces son muy pocos los años en los que los gastos no superan a los ingresos, teniendo que cubrirse el déficit con remesas de numerario. Este descubierto hubo de ser muy superior al que la contabilidad refleja, puesto que las datas están claramente subestimadas al no computarse el importe de los tabacos remitidos a Navarra para su posterior venta.

En el arriendo de 1744 el precio de la libra de «tabacos esquisitos de chupar, lavado fino, fabricado en Sevilla de toda satisfacción, rancio y hoja de cuerda del Brasil se fijaba en 15 rs. plata, ligeramente superior a la tarifa vigente en los años 1742-43 y muy similar, probablemente, al que regía en Castilla 28. Ello favoreció, sin duda, el contrabando de tabacos desde Francia y Vascongadas hacia Navarra, y éste es el hecho que estaria reflejando la caida de los ingresos. La tendencia a la baja se invertiria a partir de 1748; el aumento de la vigilancia que se produce tras el paso a la administración real de la renta de aduanas es un factor a considerar. Entre aquel año y 1752 las entradas pasaron de 236.173 a 428.887 rs. plata, un alza del 82 por ciento; desde entonces y hasta 1777 el crecimiento fue escaso, poco más de un 20 puntos.

El aumento de los ingresos y el menor crecimiento de la data entre los años cuarenta y 1780 permitió que el déficit se fuera reduciendo progresivamente, llegándose incluso a obtener beneficios en la segunda mitad de la década de los setenta. Sin embargo, esto último parece responder más a compras realizadas con el fin de introducirlas clandestinamente en Castilla que a un alza del consumo interno: el aumento de los precios que alli habia tenido lugar -32 rs. vn., equivalentes a 17 rs. plata-, permitía obtener ganancias de 2 rs. plata por libra vendiendo el tabaco adquirido legalmente en Navarra. Esta circunstancia sería corregida en 1780. Por R.D. de 17 de noviembre de 1779 y para financiar la guerra contra Inglaterra, las tarifas castellanas se habian eleva-

27 Le escritura de arriendo en CC, 1743-1744, ley 76; las tarifas aparecen recogidas en AHN, Hacienda. Ordenes Generales de Rentas (OGR), libro 8015, fol. 173.

23 En 1741 la libra de habanos de Cuba se vendis a $30 \mathrm{rm}$ vn. (- 15,94 rs. plata). Alonso Alvarez (1984, p. 29). Aunque ignoramos el importe de las reatantes labores, parece que es aquella calidad la que marca el precio medio; al menos, sus valores coinciden con éste en 1780 y 1794. 
do a 39,5 rs. vn. y de seguir manteniéndose en Navarra la tasa de exacción vigente desde 1744 los fraudes se verían estimulados. Por ello el rey escribe a las cortes «sugiriendo» que en la nueva escritura de arrendamiento se omitiera la cláusula que impedia incrementar los precios en Navarra. Y asi se hizo: la libra pasó a costar 21 rs. plata, un 40 por ciento más cara ${ }^{29}$. El alza, muy superior a la que se opera en Castilla al ser el punto de partida más bajo, provocó un fuerte descenso de las ventas, probablemente de similares proporciones a las de la subida, orientándose la demanda hacia el más barato tabaco de contrabando: la caida fue acompañada por un notable auge de los decomisos, por un reforzamiento de la vigilancia y, en consecuencia, por un aumento del gasto.

\section{CUADRO 4}

Parte de las multas que por las aprebensiones de tabaco correspondia a los denunciantes (medias decenales en rs. plata y números índice)

\begin{tabular}{|c|c|c|}
\hline & Rs plate & $N^{\circ}$ indice \\
\hline 1772.1780 & $1.305,94$ & 100,00 \\
\hline $1781-1790$ & $21.071,31$ & $1.613,50$ \\
\hline $1791-1799$ & $2.002,47$ & 153,33 \\
\hline
\end{tabular}

FUENTE: AGS, DGR, 1.: remesa, leg. 4631

El declive recaudatorio fue superado en 1794-95, años en los que la renta experimenta un espectacular y coyuntural salto al ampliarse el número de consumidores con las tropas llegadas para luchar contra la Convención. Concluida la guerra, la renta se mantiene hasta fines de la centuria en unos niveles sensiblemente más altos que los del período prebélico. Entre 1790-93 y 1797-99 los ingresos crecen un 50 por ciento, porcentaje que no se puede atribuir más que parcialmente a la subida decretada a finales de 1794 y recogida en la escritura de arriendo de diciembre de 1796; pasaron entonces los precios de 40 a 48 rs. vn. - un 20 por ciento más-, logrando las cortes que la mitad del alza, 1 pe-

29 El alza dificultaba la venta al por menor. Al regularse cada adarme (1/16 de onza) a 3,5 mrs., en cada libra se obtenian $2 \mathrm{rs}$. $12 \mathrm{mrs}$. mis que el precio oficial Las cortes conseguirian que este exceso - los apicos»- fuera entregado a la hacienda foral. CC, 1780-1781, ley 8. 
seta, fuese a parar al Vínculo ${ }^{30}$. Pero desde 1799 el consumo, al menos el legal, empezó a contraerse, tocando fondo en 1803.

\section{CUADRO 5}

Consumo de tabacos en Navarra, 1797-1807

(en libras-onzas castellanas y números índice, 1798 - 100)

\begin{tabular}{|c|c|c|c|c|}
\hline & Tabaco & & Rape & \\
\hline 1797 & $18.382-083 / 4$ & 89,03 & 223.08 & 96,14 \\
\hline $1798 \ldots$. & $20.648-013 / 8$ & 100,00 & $232-07 \quad 1 / 2$ & 100,00 \\
\hline $1799 \ldots$ & $18.038-043 / 4$ & 87,36 & $232.071 / 2$ & 100,00 \\
\hline 1800 & $14.434 .021 / 2$ & 69,90 & $119-00$ & 51,18 \\
\hline . & 14.040 .06 & 68,00 & 119.08 & 51,41 \\
\hline 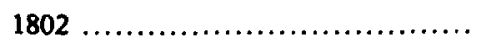 & $11.512-00$ & 55,75 & $75-00$ & 32,26 \\
\hline $1803 \ldots \ldots \ldots \ldots \ldots \ldots$ & $10.333-13$ & 50,04 & 85.08 & 36,79 \\
\hline 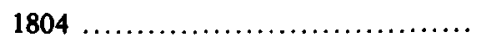 & 11.605 .12 & 56,21 & $69-00$ & 29,68 \\
\hline 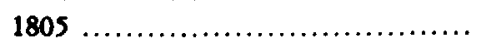 & 13.545 .09 & 65,60 & $86-00$ & 36,99 \\
\hline 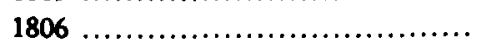 & $14.026-033 / 4$ & 67,93 & $79-071 / 2$ & 34,19 \\
\hline 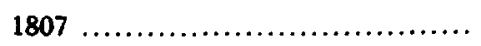 & $14.353-02$ & 69,51 & 95.00 & 40,86 \\
\hline
\end{tabular}

FUENTE: AGN, Cuentas del Vinculo, libro n. 5.

Paralelamente el déficit fue en aumento. Desconocemos si en los inicios del XIX continúan llegando remesas de dinero para enjuagar el descubierto, pero en estos momentos se adopta una nueva política. Debido a las dificultades financieras por las que atraviesa la corona ${ }^{31}$, en 1803 dejaron de abonarse a la hacienda foral los 46.500 rs. plata del arriendo y el sobreprecio del tabaco. Las continuas quejas de la Diputación reclamando el pago de las cantidades adeudadas no fueron atendidas; en 1808 los débitos se elevaban a 385.218 rs. plata ${ }^{32}$.

El control por la real hacienda del estanco del tabaco fue acompañado de

30 Y que la contabilidad del reino anota como esobreprecio del tabacos. CC, 1794-1797, ley 69, AGN, Vinculo, leg. 7, c. 22.

"Para la critica situación hacendistica de Carlos IV, Marino (1981), Barbier y Klein (1981), Artola (1982, pp. 321-459) y, sintetizando sus anteriores aportaciones, Herr (1989, pp. 100-158). Un reciente análisis del problema de la deuda pública, en Tedde (1987).

32 AGN, Cuentas del Vinculo, libro 5. 
reformas en la renta de aduanas, continuación lógica de las medidas que se habían tomado tres años antes en los territorios de la corona de Aragón. Tras suprimir por R.D. de 19 de noviembre de 1714 los puertos secos existentes entre aquéllos y Castilla, en 1717 se decretaba lo mismo para las demás aduanas interiores: por R.D. de 31 de agosto, las vascongadas se trasladaban a la costa y las navarras, al Pirineo. Pero los motines populares en el Pais Vasco ${ }^{33}$ y las presiones del gobierno francés ${ }^{34}$-las protestas navarras fueron más bien tímidas 35 - hicieron que se diera marcha atrás; por R.D. de 16 de diciembre de 1722, en enero del veintitrés retornaban a su anterior emplazamiento. En esta decisión la «casualidad afortunada [...] de baber estado los vascongados en los ministerios $y$ otros grandes puestos...”, como señalaba Canga Argüelles ${ }^{36}$, sería un factor nada desdeñable: de los siete miembros que componian la junta formada por orden de 7 de octubre de 1720 para estudiar si convenia mantener las aduanas en la frontera o volver a situarlas en el cordón del Ebro, tres eran navarros ${ }^{37}$.

Fracasado el intento de traslado, a partir de 1748 se aplicarian en la renta de tablas similares disposiciones a las adoptadas en el estanco del tabaco. Por real cédula de 2 de noviembre la corona decidió controlar directamente las aduanas, comprometiéndose a entregar a la Cámara de Comptos, encargada hasta entonces de su gestión, 236.500 rs. plata anuales para abono de los sueldos de los magistrados de los tribunales, de las mercedes consignadas sobre la renta y de los réditos a los censualistas acreedores al ramo de tablas ${ }^{38}$. Aunque, al igual que sucediera con el estanco, los fraudes fuesen el único argumento esgrimido, debemos enmarcar tal medida en el más amplio contexto de paso a la administración real de las principales rentas de la monarquía ${ }^{39}$. Pocos meses después las causas de contrabando se agregaban a la subdelegación de la renta

33 Sobre la machinada de 1718, véase Fernández de Pinedo (1974, pp. 391-404).

34 Del Rio Aldaz (1985, pp. 172-173).

35 En 1718 Juan Esteban de Cegama, agente del reino en Madrid, recomendaba a la Diputación whir con gran lentitud» en sus reivindicaciones. AGN, Traslación de aduanas, leg. 1, c. 11.

* Canga Argüelles (1968, cap. II, p. 409). El subrayado es nuestro.

37 El marqués de Andia, Francisco de Aperregui y Sebastián de Eusa Torreblance Archivo Histórico de la Diputación Foral de Vizcaya, Varios. Ordenes y Circulares, núm. 204, fols. 207r208r. A favor también de su anterior emplezamiento, el informe emitido por Luis de Salazar y Castro. Muñoz Pérez (1955, p. 775). Según se deduce de la correspondencia del agente del reino en Madrid, era Sebaution de Eusa quien le tenia al corriente de las actividades de la Junea. AGN, Trasleción de eduanas, leg $1, c .11$.

38 AHN, OGR, libro 8.016, fol. 212r.

39 Cf. Fernindez Albadalejo (1977, pp. 68-79), Artola (1982, pp. 286 y ss.). 


\section{GRAFICO 2}

Ingresos y gastos de la renta de aduanas, 1700-1799(rs. plata)

Rs. plata

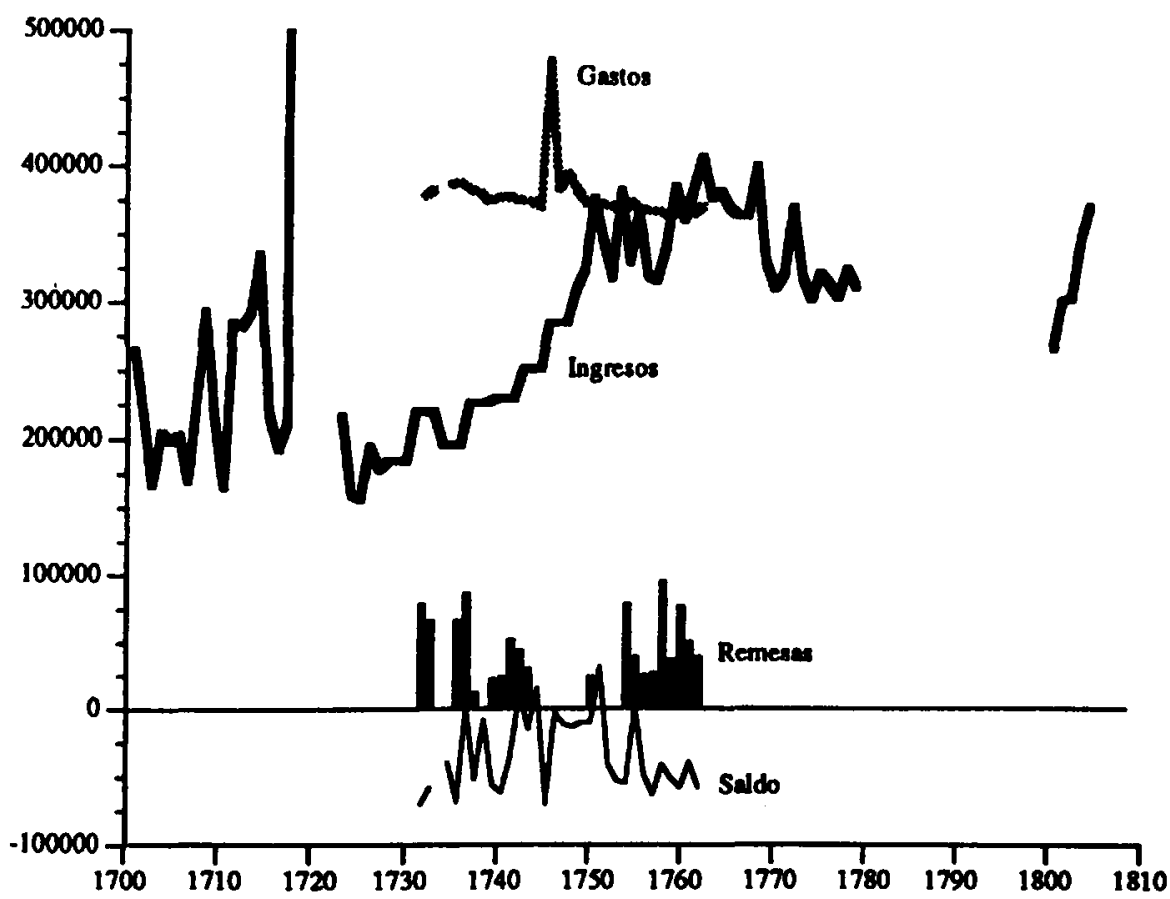

Fuente: Garcia-Zúñiga (1991: II, 128-31).

de tablas y a fines de 1749 se elevaban las penas a los defraudadores, aplicándoles, «sin embargo de sus fueros», las vigentes en Castilla ${ }^{40}$.

El éxito o el fracaso de esta política, si se produjo o no un descenso del tráfico ilícito, es algo que sólo podemos intuir. Obviamente alguna mejora se tuvo que notar, teniendo en cuenta que al aumento del resguardo en la renta de tablas hay que añadir los guardas del tabaco, cuya labor de vigilancia no se limitaba únicamente al estanco. Pero, aunque ambos cuerpos se yuxtaponian y complementaban, el contrabando, como escribía Yanguas, «siguió de la misma manera, sobre poco más o menos, porque el Gobierno no pudo, ni ha podido

40 RR.CC. de 23 de marzo y de 11 de noviembre de 1749, respectivamente. AHN, OGR, libro 8.017, fols. 150r y 394-398. 
hasta hoy, evitar la infidelidad de sus agentes» ${ }^{41}$. Al menos, los ingresos no aumentaron suficientemente y es posible que lo hicieran por debajo de lo esperado.

No se aprecian diferencias entre la tasa de crecimiento de 1724-1748, cuando las tablas estaban dadas en arriendo -2,33 por ciento anual-, y la del periodo 1749-1763, fecha en la que alcanzan el máximo secular, 2,29 por ciento. Puesto que el sistema de arrendamiento nos oculta los valores reales del träfico, suponemos por ello que el alza fue aún mayor en la primera mitad de la centuria. Frente a esta trayectoria, como el primer paso fue el aumento de la vigilancia, el gasto se disparó, tal y como había sucedido en el estanco del tabaco. Los salarios del resguardo igualaban prácticamente a los del personal administrativo y ambos representaban cerca del 97 por ciento del dispendio, una vez deducidos de los ingresos el pago de la renta y los gastos de administración ${ }^{42}$. Así, entre 1749 y 1780 el saldo fue siempre negativo, debiendo compensarse el déficit con inyecciones de dinero desde Castilla.

Las cargas que suponía el mantenimiento de un cuerpo de vigilancia, tanto dentro del reino como en la raya con Castilla y Aragón, eran muy elevadas y sus resultados, dudosos. Evidentemente, sufragar los gastos de guardas únicamente en los límites con Francia se revelaba como algo mucho menos costoso $y$, sin duda alguna, más eficaz. De ahi que, tras el control de la renta y después del fallido intento de 1717 , el siguiente paso fuera abordar el tema del traslado, lo que se hizo en las primeras cortes que se celebraron, las de 1757. Conforme a las directrices recibidas ${ }^{43}$, en su discurso de apertura el virrey transmitió a los Tres Estados el real deseo de que las aduanas se situasen en la frontera francesa, pero el rechazo fue prácticamente unánime ${ }^{44}$.

Las actitudes empezaron a cambiar a partir de los decretos de libre comercio con América de 1778. Al quedar San Sebastián incluido entre los puertos autorizados para traficar directamente, las instituciones del reino intentaron conseguir su habilitación para exportar los productos navarros a América. Pero la respuesta que llegó de la corte fue bien expresiva: «es mui justo se les conceda las mismas facultades que a los demas vasallos del Reyno, pero que sea precisamente bajo los mismos terminos» "5; es decir, sin traslado no hay ventajas. Gravadas con un 15 por ciento las introducciones en Castilla de los productos navarros, la R.O. de 29 de julio de 1779 recargará con los derechos

\footnotetext{
4 Yanguas y Miranda (1964, cap. I, p. 180).

12 Garcia-Zúñiga (1991, cap. II, p. 132).

4) Véase la instrucción secreta al virrey de 6 de abril. AGS, SSH, leg. 506.

14 Rodriguez Garraza (1974, pp. 99 y 105).

4s AGN, Tablas, leg. 6, c. 14.
} 
de extranjeria su salida hacia América, hechos que estän bien presentes cuando, reunidos en 1780 los Tres Estados, el virrey les invite de nuevo a votar el traslado de las aduanas: *... por este medio lograría un comercio ventajoso con Castilla y Aragón y que fuesen tratados para America sus efectos [...] como castellanos» ${ }^{46}$.

En las tensas discusiones que se produjeron las posturas quedaron pronto definidas. A favor se posicionaron los terratenientes y los representantes de la zona meridional, donde la agricultura habia hecho grandes progresos, que veian la integración en el mercado castellano como la única salida posible, aunque para conseguirlo tuvieran que liquidar un importante componente de la normativa foral; en el bando contrario, los valles pirenaicos, y, sobre todo, los comerciantes vinculados con el sudoeste francés y los contrabandistas, que escondían sus verdaderos intereses enarbolando la bandera de los fueros y los derechos de los consumidores ${ }^{47}$. Que estos últimos iban a salir perjudicados era una realidad innegable; aplicar los aranceles castellanos equivalía a un aumento de los impuestos indirectos y a una alza, en consecuencia, de la carestia de la vida.

Tras perder la votación, los partidarios del traslado presentaron un proyecto alternativo. Las aduanas se instalarian en los Pirineos, exigiéndose en ellas el 15 por ciento tanto de los productos importados como de los exportados, pero con algunos, e importantes, matices. Habia de permitirse introducir libremente desde Francia «todo género de ganado mayor y menor, carnes, tocinos, pescados frescos, sebo, grasas, huevos y aves y materias primeras manufacturables en el Reinow, al tiempo que se prohibiria la venta en Navarra de los vinos castellano y aragonés. No se estancarían la sal, el aguardiente, ni el plomo, habilitándose, además, un puerto guipuzcoano para el comercio a América ${ }^{48}$. Votada la nueva propuesta, el resultado fue de 38 a favor y 32 en contra, pero como para ser aprobada se requería unanimidad en cada uno de los tres brazos, la cual sólo se produjo en el nobiliario, aquélla fue rechazada.

Debido a la adversa coyuntura política, el asunto no volverá a plantearse ni en las cortes de 1794-97 ni en las de 1801, pero a partir del arancel de 1782 y de los decretos sucesivos las dificultades de la economía navarra fueron en aumento. Conforme el cerco se iba estrechando, engrosaba el número de los que veían en el traslado la única salida posible. A pesar de ello éste nunca se llevaria a efecto durante el feudalismo desarrollado, aunque en las cortes de 1828-29 se estuviera muy cerca de conseguirlo. Yanguas apunta las posibles

46 Rodriguez Garraza (1974), p. 103).

4 Del Rio Aldaz (1984, p. 388; 1985, pp. 219-220).

4 La propuesta, en Rodriguez Garraza (1975, pp. 120-121). 
causas: «Con la traslacion de las aduanas se quitaba una barrera [en concepto de los navarros] que abría la puerta a todas las demas pretensiones de Castilla [...] Castilla no ha tenido la suficiente energia para la traslacion de aduanas* 49, debilidad a la que no seria ajena la presencia en la corte de vascongados y navarros; ya habia sucedido en 1720 .

Las reformas borbónicas trastocaron las bases del real erario en Navarra, que, paradójicamente, comenzó a extraer la mayor parte de sus recursos de una renta que no le pertenecía, el estanco del tabaco. El incremento demográfico, de los intercambios y de los precios durante la coyuntura alcista del mil setecientos elevaron los rendimientos del tabaco y aduanas, lo que permitió que la corona tuviera que recurrir menos a las cortes en demanda de ayudas, y a partir de 1716 tan sólo las reunió en seis ocasiones. Incrementando los ingresos y modernizando el gasto, se logró que el reino contribuyera durante el XVII de una forma creciente a las cargas generales de la monarquia. Sin embargo, y conviene matizar, la mayor implicación de los navarros no se hizo sólo obligándoles a pagar más a la real hacienda, sino descargando sobre el fisco foral y las haciendas concejiles gastos que en otros territorios corrian por cuenta de la corona: la autodefensa, y ya desde los años ochenta del siglo xVII, el coste de la red viaria.

Impulsada por la corona, y al igual que en el resto de la monarquia so, la mejora de la red se habia iniciado en los años cincuenta, pero no será hasta fines de 1783 cuando la hacienda foral reciba plenas competencias en esta materia. La modernización ocasionó nuevos y crecidos desembolsos que exigieron, a su vez, el establecimiento de nuevos impuestos, al tiempo que parte de los ya existentes se consignaban también para este fin. Por real cédula de 1 de octubre de 1784, a los arbitrios en vigor desde $1757^{\text {s1 }}$ se añadian un portazgo para los géneros que se introdujeran en el reino del extranjero y otro para los que transitasen por él y gravámenes sobre las extracciones de pieles, regaliz, vino, vino rancio, aguardientes, aceite y jabón, al tiempo que se transfieren a la recién creada caja de Caminos parte de los ingresos con que estaba dotado el Vínculo, dando lugar asi a una descapitalización de este último ${ }^{52}$. Evidente-

49 Yangues y Miranda (1838). Cf. les conclusiones de Del Río Aldaz (1985, p. 334).

so Véase al respecto Madrazo (1984, cap. I, pp. 235 y ss.).

51 Un maravedi en cada almud de cebada que se consumiese en los mesones situados en los caminos nuevos o en sus proximidades y los derechos de carruaje que se percibian en las cadenas de Tafalla y Tudela.

32 El impuesto de 4 rs. en cada saca de lanas y aninos, con la condición de satisfacer anualmente 8.000 rs. al Vínculo, y los upicos» del rabaco vendido al por menor, mientras el estanco del chocolate habia de contribuir cada año con 26.000 rs. En 1789 se aqregó el gravamen sobre los géneros y mercancias importados por los naturales, concedido por la corona para la reintegra- 
mente, estos recursos no producian las sumas requeridas para llevar a cabo las obras, pero eran el aval necesario de los censos que se iban a contraer, con su producto se pagarian los intereses y se iria amortizando poco a poco el capital.

\section{CUADRO 6}

Ingresos y gastos de los Expedientes de caminos (rs. plata)*

\begin{tabular}{|c|c|c|c|c|c|}
\hline \multicolumn{2}{|l|}{ INGRESOS } & Arbitrios & Censos & Varios & Total \\
\hline \multirow{4}{*}{\multicolumn{2}{|c|}{$\begin{array}{l}1784-1789 \\
1790-1796 \\
1797-1807\end{array}$}} & 1.353 .721 & 5.553 .427 & 15.569 & 6.922 .717 \\
\hline & & 2.136 .805 & 120.000 & 60.744 & 2.317 .549 \\
\hline & & 4.393 .440 & 3.449 .058 & 76.069 & 7.918 .567 \\
\hline & & 7.883 .966 & 9.122 .485 & 152.382 & 17.158 .833 \\
\hline GASTOS & $\begin{array}{c}\text { Gastos } \\
\text { caminos }\end{array}$ & Salarios & $\begin{array}{c}\text { Réditos } y \\
\text { amontización }\end{array}$ & Varios & Total \\
\hline \multirow{4}{*}{$\begin{array}{l}1784-1789 \ldots \ldots \ldots \ldots \ldots \\
1790-1796 \ldots \ldots \ldots \ldots \ldots \\
1797-1807 \ldots \ldots \ldots \ldots \ldots\end{array}$} & 5.334 .661 & 92.357 & 510.234 & 40.000 & 5.977 .252 \\
\hline & 1.638 .255 & 109.413 & 1.254 .521 & 40.000 & 3.042 .189 \\
\hline & 5.060 .553 & 140.082 & 2.606 .634 & 120.729 & 7.927 .998 \\
\hline & 12.033 .469 & 341.852 & 4.371 .389 & 200.729 & 16.947 .439 \\
\hline
\end{tabular}

Fuente: Contaduria. Expedientes de caminos, libros 1-2.

- Excluidos remanentes, entradas por salida y trasvases entre cajas.

Concluidas para 1794 las reparaciones en el camino de la Ribera y la transformación del camino de herradura hacia Guipúzcoa en uno carretil y reunidas de nuevo las cortes, en ellas se proyectan dos nuevos caminos, los de Logroño y Sangüesa, dada ala necesidad de ellos para la exportacion de los frutos, y especialmente de los vinos, que es la principal cosecha de uno y otro terrenow. De esta forma, en 1797 se vuelven a tomar censales. Sin embargo, el aumento del pasivo no se vio acompañado por el establecimiento de nuevas fuentes de ingreso, ya que en este punto las cortes de 1794-97 se limitan a perfeccionar técnicamente el cobro de peajes 53 .

ción del donativo ofrecido por las cortes de 1780-1781. CC, 1794-1797, ley 47; AGN, Caminos, leg. 3, c. 13.

33 AGN, Caminos, leq. 6, c. 24. 
Entre 1784 y 1807 los desembolsos hechos por la hacienda foral en la construcción y mantenimiento de la red viaria ascienden a 12,375.321 rs. plata, algo más de 23 millones de rs. vn., cifra que se redimensiona si consideramos que equivale al 80 por ciento de los caudales que en concepto de donativo habia obtenido la monarquía en el reino entre 1700 y 1806.

A las deudas contraidas por la caja de Caminos hay que añadir la generada por la guerra contra la Convención, que, aunque de no muy elevada cuantia, persistirá durante buena parte del xIx. Legalmente responsables de la defensa de su territorio, los navarros tuvieron que hacer frente a los ataques de un enemigo que llegó a ocupar parte de su territorio. Además de contribuir con hombres -6.720 voluntarios divididos en siete batallones y en torno a 16.000 paisanos-, el Vinculo hubo de sufragar los uniformes de los batallones, socorrer con $2 \mathrm{rs}$. vn. diarios de sobreprest a las tropas y adelantar el dinero necesario para la compra del armamento, cuyo valor seria más tarde reintegrado por el rey. Para atender a estos gastos, extrajo 456.719 rs. plata del Depósito General, pidió prestados 128.000 a la caja de Caminos y, siendo estas sumas insuficientes, recurrió al crédito, tomando censos por importe de 491.711 rs. Mediante estos mecanismos, más la plata entregada por las iglesias, los donativos patrióticos y los bienes incautados a los franceses que residian en Navarra, pudo hacerse frente al dispendio bélico, cuyo costo hemos estimado en 2.300.000 rs. plata ${ }^{34}$. Firmada la paz, los recursos ordinarios no bastaban para amortizar la deuda, restituir el dinero a los franceses y el importe de la plata a las iglesias y reintegrar las sumas transferidas de Caminos, por lo que en 1795 autoriza el rey a las cortes para que realicen una derrama de 1.600 .000 rs. 55 , que, en principio, habían de ser suficientes para cubrir los gastos. Asi, para 1800 el pasivo se habia rebajado a 633.599 rs. -141.888 que quedaban por restituir al clero y el total de los censos tomados, cuyos intereses se abonaban puntualmente-, situación financiera que no parecía problemática, ya que las cuentas anotaban 385.358 rs. como alcance del anterior ejercicio. Sin embargo, ni se podria saldar la deuda con la iglesia, ni redimir más que unos pocos censos, ya que desde principios del XIX los balances fueron siempre negativos -en 1803 la corona había dejado de pagar las anualidades del arriendo del

34 Garcia-Zúñiga (1991, cap. I, pp. 327-328). A ellos habria que añadir una cantidad imposible de calcular, pero probablemente de similares proporciones, que recayó totalmente sobre los pueblos al tener que gratificar a los mozos para que se alistasen y hacer frente a los desembolsos que suponian los apellidos - la obligación foral de defender el territorio a sus propias expensas ante cualquier incursión enemiga, que, al menos teóricamente, afectaba a todos los navarros capaces de tomar las armas-, lo que agravó el endeudamiento municipal.

5s CC, 1794-1797, ley 26. Su importe más el dinero procedente de las ofertas patrióticas y los caudales extraidos de las arcas superaba ligeramente el coste de la guerra. 
tabaco- y el déficit continuado que se produce fue consumiendo el metálico existente en la caja.

Desde que en 1784 asumiera la construcción de su red viaria, Navarra había contraido una deuda de muy difícil liquidación al no contarse con medios suficientes para ello: en 1807 el principal se habia reducido en un 5,6 por ciento, pero entre esta fecha y 1834 tan sólo se amortizó menos de un 1 por ciento. Si a los empréstitos de la caja de Caminos agregamos los censos tomados por el Vínculo durante la guerra contra Francia que quedaban sin redimir, más un préstamo de pequeña cuantía tomado en 1801, la conclusión no puede ser más clara: en 1808 la hacienda foral atravesaba una profunda crisis que la guerra de Independencia no haria sino agudizar 56.

\section{REFORMAS Y PRESION FISCAL}

Los cambios experimentados por la fiscalidad navarra en el setecientos se tradujeron en un aumento de la presión fiscal. Dado el carácter coactivo de la mayor parte de los ingresos, tanto de la real hacienda como de la hacienda foral, el comportamiento de la carga tributaria (véase apéndice) sigue bastante de cerca la trayectoria de aquéllos. Ahora bien, no todas las contribuciones que la integran recaian efectivamente sobre los navarros. Algunas son fáciles de desagregar, como los gravámenes sobre las exportaciones de lana, que cabe suponer eran pagados por los compradores extranjeros como resultado de la traslación impositiva. No sucede lo mismo con la renta de tablas, y repercutir todos los ingresos aduaneros sobre sus habitantes seria un grave error, siendo Navarra zona de tránsito de las mercancias que por tierra se dirigian de Europa a Castilla, y a la inversa, buena parte de las entradas lo eran por este concepto. Asi, para no sobreestimar la presión que soportaron los navarros, hemos corregido la carga tributaria con estimaciones del porcentaje que de los ingresos arancelarios pudieran pagar realmente aquéllos 57 .

Apoyada en dacios sobre el tráfico y el consumo, la coyuntura expansiva del xviI posibilitó un notable incremento de la carga fiscal, aunque no será más que partir de $1730-39$ cuando ésta progrese de forma decidida. Dentro de una marcada tendencia alcista se pueden señalar dos períodos en los

36 Sobre el gasto y financiación de la guerra contra el francés, De la Torre (1991, pp. 25-94).

"7 Garcia-Zúñiga (1991, cap. I, pp. 368-369). No ha sido posible, en cambio, realizar la misma operación con las execciones exigidas en las aduanas para la caja de Caminos -derechos de tablas y nuevo impuesto-, al mezclarse en ellas gravámenes sobre la importación y sobre la exportación. 


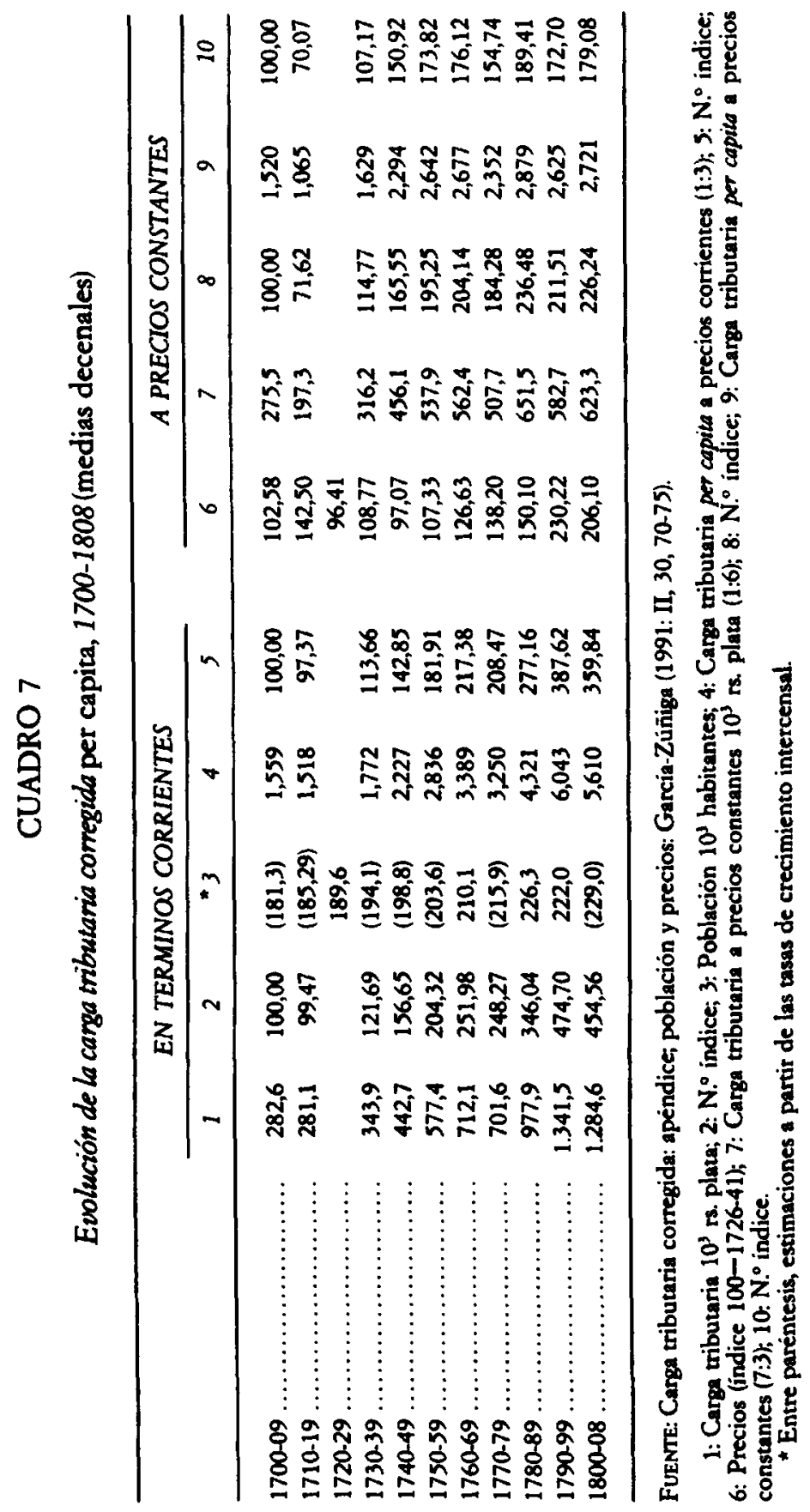


que las tasas de crecimiento fueron muy superiores a la media secular. El primero se extiende desde 1730-39 hasta 1760-69 y su causa radica en los crecientes rendimientos del estanco del tabaco. Tras un leve retroceso en los años setenta, la detracción fiscal se eleva de nuevo en los ochenta por el alza de los valores del donativo, de la renta del tabaco y de las nuevas exacciones que se introducen en las aduanas para financiar la red de carreteras. El cenit se sitúa a fines de siglo en el marco de una coyuntura adversa de deficientes cosechas y guerra. Desde que se iniciara el mil setecientos a visperas de la guerra contra el francés la carga fiscal se ha multiplicado por 4,5 , avance que el débil crecimiento demográfico apenas atenúa - más a partir de la década de los sesenta que en las precedentes-; en términos per capita se pasó de índice 100 a indice 36058 .

\section{CUADRO 8}

Diferencias porcentuales entre la carga tributaria deflactada per capita de Navarra respecto a Castilla, Cataluña y Guipuizcoa *

\begin{tabular}{|c|c|c|c|c|c|c|}
\hline & \multicolumn{2}{|c|}{ Cataluria } & \multicolumn{2}{|c|}{ Castille } & \multicolumn{2}{|c|}{ Guipuizcoa } \\
\hline & $A$ & B & $A$ & B & $A$ & B \\
\hline $1730-39 \ldots \ldots \ldots$ & $-90,00$ & $-88,38$ & $-87,18$ & $-87,06$ & $+103,80$ & $+81,01$ \\
\hline $\begin{array}{l}\cdots \ldots \\
1750-59 \ldots \ldots \ldots\end{array}$ & $-78,42$ & $-73,89$ & $-79,22$ & $-78,13$ & $+270,83$ & $+234,72$ \\
\hline $1760-69 \ldots \ldots \ldots$ & $-71,62$ & $-63,14$ & $-72,77$ & $-70,46$ & $+284,29$ & $+248,57$ \\
\hline $1770-79 \ldots \ldots \ldots$ & $-73,94$ & $-64,55$ & $-79,00$ & $-77,16$ & $+298,33$ & $+253,33$ \\
\hline $\begin{array}{l}\cdots \ldots \\
1790-99 \ldots \ldots \ldots . .\end{array}$ & $-49,62$ & $-15,67$ & $-63,97$ & $-52,84$ & $+561,67$ & $+536,67$ \\
\hline
\end{tabular}

Fuente: Gercia-Züñiga, Mugartegui y De la Torre (1991: 86-87). Las diferencies con las cifras alli presentadas obedecen a una reevaluación a la baja de la parte que de los derechos aduaneros pagaban los navarros y a la inclusión en el último decenio de las exacciones impuestas para la caja de Caminos.

* La comparación se ha hecho incluyendo las rentas generales (A) y desagregindolas (B), ha. bida cuenta de lo problemático que resulta hacer recaer la totalidad de los ingresos aduaneros del Principado y Navarra sobre sus respectivos habitantes, ya que buena parte de los productos importados tenian como destino final Cestille.

36 El desconocimiento de los grandes agregados macroeconómicos nos impide realizar nues. tro anälisis en términos de presión fiscal. 
Descontando el movimiento de los precios, no se observan diferencias en la primera mitad del xvill, ya que, si exceptuamos los años 1710-19, éstos se mantuvieron estables. A partir de entonces la imagen varía de una forma radical. Si en rs. plata corrientes la tasa de crecimiento de la segunda mitad de la centuria -1,6 por ciento- sobrepasa ligeramente la de la primera $-1,4$ por ciento anual-, a precios constantes no cabe hablar sino de estabilidad. Mientras en el primer setecientos el volumen de la carga fiscal se ha duplicado, entre los años cincuenta y 1800-08 el alza es tan sólo de 16 puntos - tasas de 1,3 y 0,3 por ciento, respectivamente-. Así, la inflación nos está enmascarando un descenso del consumo individual. Aunque modesto, el mayor dinamismo demográfico de la segunda mitad de la centuria logra absorber este pequeño aumento y la carga fiscal por habitante se mantiene estacionaria entre 1750 y 1808 , bien que con un ligero retroceso en los años setenta y un repunte en los ochenta. En consecuencia, si a precios constantes la ratio carga tributaria/vecinos se elevó un 79 por ciento durante el siglo xvili, en su mayor parte este ascenso se produce en la primera mitad.

Ahora bien, contrastando la tendencia de la carga tributaria per capita en Navarra con la que tuvo en Castilla, Cataluña y Guipúzcoa, se comprueba cómo fue en el viejo reino pirenaico donde el peso de la fiscalidad experimentó una mayor subida en el mil setecientos, y tanto en términos corrientes como deflactada. La responsabilidad de este hecho no hay que atribuirla exclusivamente al diferente comportamiento de las variables población y precios, sino también al éxito evidente de la política fiscal que en Navarra llevó a cabo la corona a lo largo de la centuria.

Pese a todo la desigualdad tributaria persistió y, si bien las distancias se fueron recortando conforme avanzaba el siglo, éstas continuaron siendo muy fuertes, más con Castilla que con Cataluña. Los contribuyentes navarros seguirian gozando de una situación fiscalmente privilegiada en el seno de la monarquia que tan sólo el País Vasco superaba. Unicamente en el aspecto militar se habria conseguido homologarlos. Aunque persistieran las formas medievales del servicio en hombres, desde el establecimiento de las quintas en 1773 entre los navarros y el resto de los súbditos de la monarquía - Vascongadas aparte- no habia ya ninguna diferencia en este terreno.

\section{BIBLIOGRAFIA}

Alonso Alvarez, L. (1984): \&De la manufactura a la industria: la Real Fäbrica de Tabacos de La Coruña (1804-1857)m, Revista de Historia Económica, vol. 2, n.03, pp. 13-34. 
ANES, Gonzalo (1974): aLa contribución de frutos civiles entre los proyectos de reforma tributaria en la España del siglo xviı», Hacienda Pública Española, n. ${ }^{\circ} 27$, pp. 21-45.

Artola, Miguel (1982): La Hacienda del Antiguo Régimen, Madrid: Alianza/Banco de España.

Artola, M., y Bulbao, L. M. eds. (1984): Estudios de Hacienda de Ensenada a Mon, Madrid: Instituto de Estudios Fiscales.

BAYARD, Françoise (1988): Le monde des financiers au XVIle siècle, Paris: Flammarion.

BARBIER, Jacques A. (1977): *The Culmination of the Bourbon Reforms, 1787-1792*, Hispanic American Historical Review, vol. 57, n. ${ }^{\circ} 1$, pp. 51-68.

Barbier, J. A.: y KLeIN, Herbert S. (1981): «Revolutionary Wars and Public Finances: The Madrid Treasure, 1784-1807», Joumal of Economic History, vol. 41, n. ${ }^{\circ} 2$, pp. 315.39.

- (1985): «Las prioridades de un monarca ilustrado: el gasto público bajo el reinado de Carlos III*, Revista de Historia Económica, vol. 3, n. 3, pp. 473-95.

BilbAO, Luis M.` (1984): «La fiscalidad de las provincias exentas de Vizcaya y Guipúz. coa durante el siglo xvinw, en ArTOLA, M: y BilbAo, L. M. eds. (1984), pp. 67-83.

- (1991): «Haciendas forales y hacienda de la monarquia. El caso vasco, siglos xvIxvm», Hacienda Pública Española. Monografías 1, pp. 43-58.

Braudel, Fernand (1976): El Mediterráneo y el mundo mediterráneo en la época de Felipe II, Madrid: Fondo de Cultura Económica.

Brewer, John (1989): The Sinews of Power. War, Money and the English State, 1688-1783, Londres: Unwin Hyman.

Canga Argoelles, José (1834/1968): Diccionario de Hacienda con aplicación a España, Madrid: Instituto de Estudios Fiscales, facsímil.

CORREA BALlester, Jorge (1986): El impuesto del equivalente y la ciudad de Valencia, 17071740, Valencia: Generalitat Valenciana.

Cuadermos de las Leyes y Agravios reparados por los Tres Estados del Reino de Navarra, Pam. plona: Aranzadi, 1964.

DE LA TORRE, Joseba (1991): Los campesinos navarnos ante la guema napoleónica. Financiación bélica y desamortización civilh Madrid: Ministerio de Agricultura, Pesca y Alimentación.

Del Rfo, Ramón (1984): «El problema de las aduanas en las Cortes de Navarra de 1828-1829. Replanteamiento de la cuestión», en IX Congreso de Estudios Vascos $\star A n-$ tecedentes próximos de la sociedad vasca actual. Siglos XVII y XIX», San Sebastiän: EuskoIkaskuntza, pp. 387.89.

- (1985): Las últimas Cortes del Reino de Navarra (1828-1829), San Sebastián: Haramburu.

Dessert, Daniel (1984): Argent, pouvoir et société au Grand Siècle, Paris: Fayard.

Fernandez Albadalejo, Pablo (1977): «El decreto de suspensión de pagos de 1739: análisis e implicaciones*, Moneda y Crédita, n. ${ }^{\circ} 142$, pp. 51-85.

Fernandez de PINEdo, Emiliano (1974): Crecimiento económico y transformaciones sociales del País Vasco (1100-1850), Madrid: Siglo Veintiuno.

- (1979): «Un cas regional avec faible pression fiscale: le Pays Basque péninsulaire», Review, vol. 3, n. 1 , pp. 75-96.

- (1980): «Coyuntura y política económicas», en TUNON DE LARA, M., dr., Historia de España, VII. Centralismo, ilustración y agonía del Antiguo Régimen (1715-1833) Barcelona: Labor, pp. 9-173.

- (1985): «Els ingressos de la hisenda reial a Catalunya (1717-1779) $\nsim$, Recerques, n. 17 , pp. 125.39. 
(1987): «Haciendas forales y revolución burguesa: las haciendas vascas en la primera mitad del siglo xIX», Hacienda Priblica Española, n $108-109$, pp. 197-220.

(1991): «Gasto público y reformas fiscales. Las Haciendas forales vascasw, Hacienda Príblica Espariola. Monognafías 1, pp. 93-100.

FerNANDEz DE PINEDO, E, ed. (1990): Haciendas forales y bacienda real Homenaje a D. Miguel Artola y D. Felipe Ruiz Martín, Bilbao: Universidad del País Vasco.

FonTaNA, Josep (1972): «La supervivencia del mito de la única contribución. Noticia de algunos arbitristas españoles de comienzos del siglo xIX», Hacienda Pública Española, n. 17 , pp. 111.19.

_- (1973). Hacienda y Estado en la crisis final del Antiguo Régimen español: 1823-1833, Madrid: Instituto de Estudios Fiscales.

(1989): «Estado y hacienda en el "Despotismo Ilustrado" ", en Estado, bacienda y sociedad en la bistoria de Esparia, Valladolid: Instituto de Historia Simancas/Universidad de Valladolid, pp. 123-47.

(1990): «Modernización y progreso: política y hacienda del despotismo "Ilustrado" ", en Fern/ndez de Pinedo, E., ed. (1990), pp. 113-22.

FORCADELL, Carlos (1984): «El sistema fiscal aragonés: de la Unica Contribución a los desajustes y agravios tributarios tras la Guerra de Independenciaw, en ARTOLa, M., y BiLbAO, L. M. eds. (1984), pp. 231-47.

FORTEA, José Ignacio (1990): Monarquía y Cortes en la conoma de Castilla. Las ciudades ante la política fiscal de Felipe II, Salamanca: Cortes de Castilla y León.

Garcta-Cuenca Aruti, Tomis (1983): alas rentas generales o de aduanas de 1740 a 1774w, en ANEs, G., Rojo, L. A., y TEDDE, P., eds., Historia económica y pensamiento social. Estudios en bomenaje a Diego Mateo del Peral, Madrid: Alianza/Banco de España, pp. $237-62$.

Garcin-Zonigh, Mario (1990): «Los ingresos de la hacienda real en Navarra (siglos XVIXVII), en FerNANDEZ dE PINEDO, E., ed. (1990), pp. 195-206.

- (1991): Fiscalidad en Navarra durante el feudalismo desamollado, 1500-1808, Tesis doc. toral inédita, Universidad del Pais Vasco.

(1993): «Gasto y deuda pública en Navarra durante el feudalismo desarrolladow, en Fortea, José Ignacio, ed., Política y Hacienda en el Antiguo Régimen Murcia: Universidad de Murcia (en prensa).

Garcla-Zúniga, M; Mugartegu, Isabel, y De la Torre, Joseba (1991): «Evolución de la carga tributaria en la España del Setecientos», Hacienda Pública Española. Monografias 1, pp. 81-91.

Garzon Pareja, Manuel (1980): La Hacienda de Carlos II, Madrid: Instituto de Estudios Fiscales.

HERR, Richard (1989): Rural Change and Royal Finances in Spain at the End of the Old Regime, Berkeley/Los Angeles: University of California Press [Hay trad. cast: Madrid: Instituto de Estudios Fiscales, 1991].

Hocovet, Jean-Claude (1987): «L'impôt du sel et l'Etatw, en Le roi, le manchand et le sel. Actes de la table ronde "L'impôt du sel en Europe, XIIle- XVIIle sièclen, Lille: Presses Universitaires de Lille, pp. 27-49.

KAMEN, Henry (1974): La guerra de Sucesión en Esparia, 1700-1715, Barcelona: Grijalbo.

KRIEDTE, Peter (1982): Feudalismo tardío y capital mercantil Barcelona: Critica.

Madrazo, Santos (1984): El sisteme de imansportes en España, 1750-1850, Madrid: Colegio de Ingenieros de Caminos, Canales y Puertos/Turner. 
Matnlla Tascon, Antonio (1947): La única contribución y el catastro de Ensenada, Madrid: Ministerio de Hacienda.

MerCADER i RIBA, Joan (1961): «L'establiment del reial Cadastre a Catalunya i la seva fonamentaciò econòmica i social», en Miscellìnia Fontsère, Barcelona: Gustavo Gili, pp. 295-303.

Merino, José Patricio (1981): «La Hacienda de Carlos IV», Hacienda Pública Española, n. ${ }^{\circ} 69$, pp. $139-82$.

- (1987) Las cuentas de la administración central española, 1750-1820, Madrid, Instituto de Estudios Fiscales.

Morineau, Michel (1980): «Budgets de l'Etat et gestion des finances royales en France au dix-huitième sièclex, Revue Historique, n. ${ }^{\circ}$ 536, pp. 289.336.

MugARTEGUI, Isabel (1990): Hacienda y fiscalidad en Guipúzcoa durante el Antiguo Régimen, 1700-1814, San Sebastián: Fundación Cultural de la Caja de Guipuzcoa.

Munoz Perez, José (1955): «Mapa aduanero del XVIII español», Estudios Geográficos, n. ${ }^{0} 61,747.97$.

NADAl FarReras, Joaquin (1981): La introducción del catastio en Gerona. Contribución al estudio del régimen fiscal de Cataluña en tiempos de Felipe $V$, Barcelona: Universidad de Barcelona.

Novissima Recopilacion de las leyes del Reino de Navarra bechas en sus Cortes Generales desde el año de 1512 basta el de 1716, Pamplona: Aranzadi, 1964.

OTAzu, Alfonso (1978): La neforma fiscal en la España moderna: el caso de Extremadura, Madrid: Instituto de Estudios Fiscales.

Ozanam, Didier (1978): «Notas para el estudio de los presupuestos de la monarquía es. pañola a mediados del siglo XviII, en OTazU, A, ed., Dinero y Crédito (siglos XVI-XIX). Actas del primer coloquio intemaciomal de Historia Económica, Madrid: Moneda y Cré. dito, pp. 49-62.

Peiro, Antonio (1988): aLa Unica Contribución», en El Cetastro en España, 1714-1906, Madrid: Centro de Gestión Catastral y Cooperación Tributaria, vol. 1, pp. 75.87.

PIEPER, Renate (1988): Die spanischen Kronfinanzen in der zweiten Hälfte des 18. Jabrbunderts (1753-1788): ökonomische und soziale Auswirkungen, Stuttgart: Steiner Verlag Wiesbaden [Hay trad. cast.: Madrid: Instituto de Estudios Fiscales, 1992].

RodrIguez GarrazA, Rodrigo (1974): Tensiones de Navarra con la Administración Central (1778-1808), Pamplona: Institución Príncipe de Viana/CSIC.

ROMEU LLORACH, Jordi (1981): El sistema fiscal valenciano, 1715-1823, Vinaroz.

Soвoul, Albert (1985): «Fondaments économiques: La Féodalité tardive», en KOPEC. zl, B., y otros, L'Absolutismécéchiné, Budapest: Akadémiai Kiadó/CNRS, pp. 35-49.

TEDDE, Pedro (1987): «Crisis del Estado y deuda pública a comienzos del siglo XIX», Hacienda Pública Española, n. ${ }^{0}$ 108-109, pp. 169-95.

YanguAS y MiRANDA, José (1838): «Anälisis histórico-critico de los Fueros de Navarraw, Boletin Oficial de Pamplona, 15 marzo-2 abril.

- (1840/1964): Diccionario de Antigüedades del Reino de Navame, Pamplona: Institución Principe de Viana. 


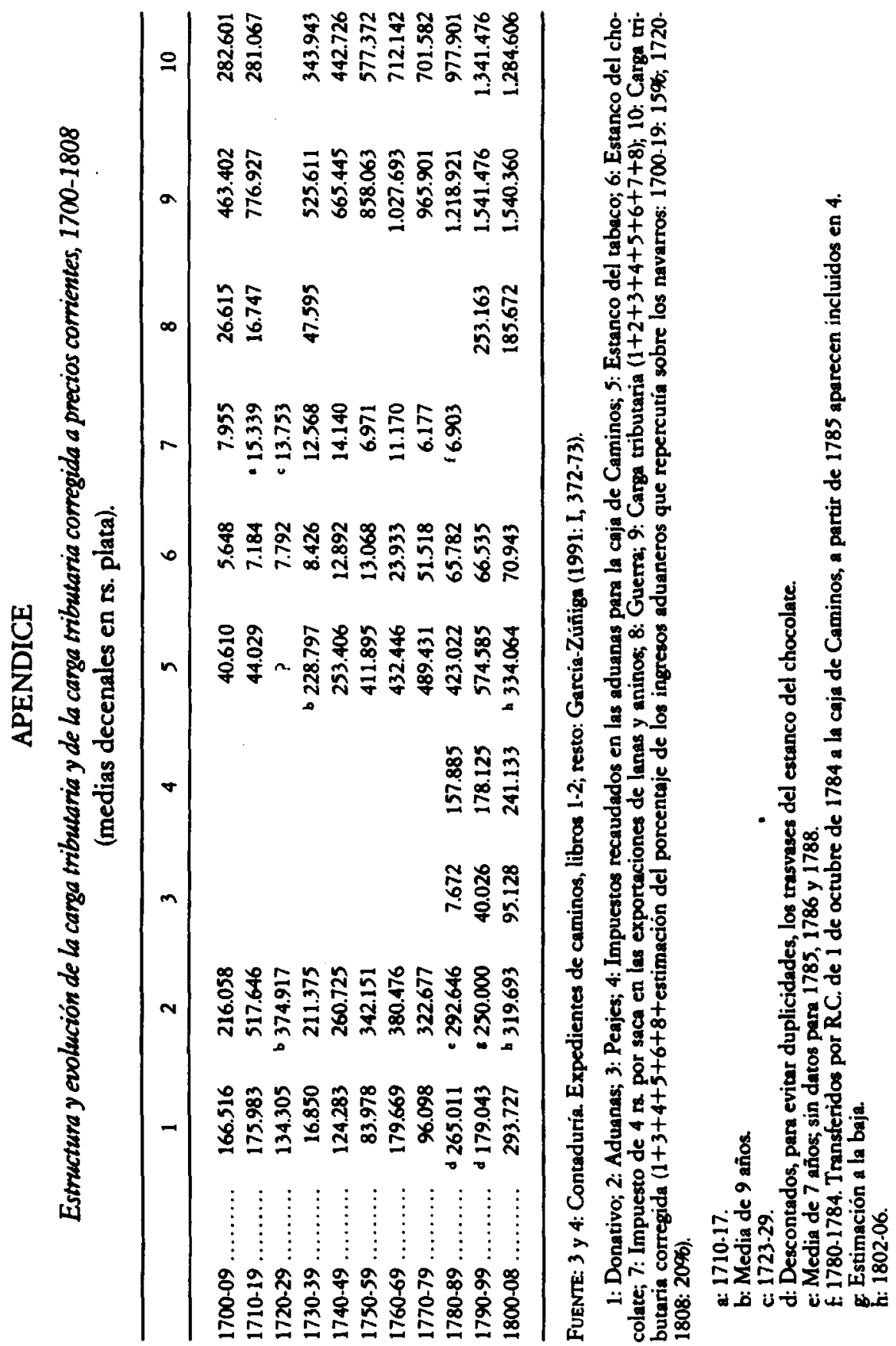

